\title{
The Effect of Prickly Pear, Pumpkin, and Linseed Oils on Biological Mediators of Acute Inflammation and Oxidative Stress Markers
}

\author{
Sana Bardaa, ${ }^{1}$ Mouna Turki, ${ }^{2}$ Sameh Ben Khedir $\left(\mathbb{D},{ }^{1}\right.$ Massara Mzid $\left(\mathbb{D},{ }^{1,3}\right.$ Tarek Rebai, ${ }^{3}$ \\ Fatma Ayadi, ${ }^{2}$ and Zouheir Sahnoun $\mathbb{1}^{1}$ \\ ${ }^{1}$ Laboratory of Pharmacology, Faculty of Medicine of Sfax, University of Sfax, Tunisia \\ ${ }^{2}$ Laboratory of Biochemistry, CHU Habib Bourguiba, University of Sfax, Tunisia \\ ${ }^{3}$ Laboratory of Histology Embryology and Reproductive Biology, Faculty of Medicine of Sfax, University of Sfax, Tunisia
}

Correspondence should be addressed to Zouheir Sahnoun; zouheir.sahnoun.fms.tn@gmail.com

Received 10 May 2020; Revised 1 July 2020; Accepted 14 July 2020; Published 3 August 2020

Academic Editor: Peter Fu

Copyright ( $) 2020$ Sana Bardaa et al. This is an open access article distributed under the Creative Commons Attribution License, which permits unrestricted use, distribution, and reproduction in any medium, provided the original work is properly cited.

\begin{abstract}
Medicinal plants have been used as a source of effective and safe alternative therapeutic agents for various ailments including inflammation. In fact, the aim of this study is to assess the topical anti-inflammatory and antioxidative potential effects of Cucurbita pepo (pumpkin), Linum usitatissimum (linseed), and Opuntia ficus indica (prickly pear) oils on acute inflammation using carrageenan-induced paw edema model. The study was conducted on 36 rats splitted in 6 groups: a normal control group and 5 carrageenan-treated groups (1\%), each treated with either a normal saline, the reference drug ("Inflocine ${ }^{\circledR ”} 2 \mathrm{mg} / \mathrm{paw}$ ), pumpkin, linseed, or prickly pear oils $(25 \mu \mathrm{l} / \mathrm{paw})$. The response to these treatments was mainly assessed by the measuring of edema paw size, hematological and biochemical analysis, oxidative stress testing, and histological study. All the studied seed oils especially prickly pear oil proved to be efficient in treating acute inflammation. The oil-treated groups revealed a significant $(p<0.05)$ decrease in the clinical signs of inflammation, hematological parameters (white blood cells and platelets), concentrations of CRP and fibrinogen, and congestion compared to the normal saline-treated group. The results also showed that the tested oils, endowed with a radical scavenging ability, could significantly increase the activities of SOD, CAT, and GPx in carrageenan-treated skin by reducing the lipid peroxidation and protein oxidation (TBARS, AOPP). The anti-inflammatory effect of the tested oils was closely related to both their antioxidant properties as well as their bioactive compounds (polyunsaturated fatty acids, vitamin E, and phytosterols). For the first time, the findings of the current study highlight the "in vivo" anti-inflammatory property of pumpkin, linseed, and prickly pear oils on carrageenan-induced acute inflammation by regulating inflammatory mediators and oxidative stress markers.
\end{abstract}

\section{Introduction}

The worldwide rise of inflammatory diseases has made them to become a global emergency. The inflammation which underlies almost every disease process has been shown to cause many common diseases. Indeed, inflammation is a protective reaction of the body to harmful stimuli [1]. Persistent and uncontrolled inflammation leads to the development of several chronic inflammatory diseases such as psoriasis, rheumatoid arthritis, and atherosclerosis [2]. Thus, it behooves researchers to develop effective anti- inflammatory treatments to control acute inflammation using medicinal plants that have been served as a source of effective and safe alternative therapeutic agents for various ailments including inflammation [3]. Accordingly, the Cucurbita pepo (pumpkin), Linum usitatissimum (linseed), and Opuntia ficus indica (prickly pear), that have prominent extracted seed oils, are studied as a possible antiinflammatory treatment. The inflammatory process induces oxidative stress and reduces cellular antioxidant capacity [4]. Thus, the current study aimed at assessing and reporting the "in vivo" anti-inflammatory and antioxidative activities 
of pumpkin, linseed, and prickly pear extracted oils on acute inflammation induced by carrageenan.

Although antioxidant and antibacterial properties of pumpkin, linseed, and prickly pear oils were reported in several studies [5-7], the acute anti-inflammatory activities using carrageenan test are still not scientifically confirmed.

Cucurbita pepo (pumpkin) is an annual climber plant globally well-known [8]. According to several reports, pumpkin seeds contain considerable amounts of polyunsaturated fatty acids (linoleic acid), monounsaturated acid (oleic acid), phytosterols, and $\alpha$-tocopherol with therapeutic values [5].

The therapeutic use of pumpkin was described in many traditional medicines. Previous studies showed that pumpkin seeds provided various pharmacological properties. It has been used as a remedy for diabetes and several urological disorders (benign prostatic hyperplasia and micturition problems) [8-10]. It was reported that pumpkin seed oil had interesting antioxidant, antibacterial, and wound healing activities $[5,11]$.

Linum usitatissimum, commonly known as linseed or flaxseed, is an annual plant that belongs to the family of Linaceae. Traditionally, flaxseed is grown for its oil. The linseed and its derivative are rich sources of the essential fatty acid (alpha-linolenic acid) and an array of antioxidants $[6,12]$. Linseed extracted oil is used in traditional medicine as an antioxidant, laxative, sedative, and emollient agent $[11,13]$.

Opuntia ficus indica (L.) Mill, known as prickly pear, is a succulent plant that belongs to the cactaceae family. This plant is widespread in dry regions, mainly in the Mediterranean area. Prickly pear seed oil is particularly characterized by a high content of vitamin E, sterols, and fatty acids. The linoleic acid is a major polyunsaturated fatty acid, oleic acid is the dominant monounsaturated fatty acid, and palmitic acid is the major saturated fatty acid $[7,14]$.

It was described that the prickly pear fruit had interesting biological properties, and thus, it was widely used in traditional medicine for its antidiabetic and hypolipidemic properties [15]. Some authors attributed its possible antioxidant, antibacterial, and wound healing effects to its interesting composition $[7,16]$.

\section{Material and Methods}

2.1. Material. The Opuntia ficus indica L. plant seeds were harvested (November 2014) in Sbeitla (region of Kasserine, North-central Tunisia). However, the Cucurbita pepo L. and brown Linum usitatissimum seeds were harvested in November 2014 in Sidi Bouzid and Mehdia regions, respectively.

The seeds were authenticated by Dr. Hamadi Ben Salah, and the voucher sample was deposited at INRAT. The seeds had been dried according to Omega Tunisie Industry standards. After that, the fixed oil was extracted by the first cold pressure from the dried seeds using a mechanical oil press (SMIR, MUV1 65). The seeds were dropped into a cylinder that contains a rotating screw. This screw grinds and crushes the seeds until the oil is extracted. Small holes in the bottom of the cylinder allow the oil to escape into a collection container. The extracted oils were kept in hermetically sealed opaque glass bottles until their use.
"Inflocine ${ }^{\circledR} ":$ topical ointment was purchased from the local pharmacy. It is a nonsteroidal anti-inflammatory indicated for acute inflammation treatment. The remaining chemicals used were of analytical grade.

2.2. Animals. The assays of this study were conducted on adult male Wistar rats weighing $168 \pm 23 \mathrm{~g}$. The animals were obtained from the local Central Pharmacy, Tunisia.

The experimental protocols were conducted following the guide for the care and use of laboratory animals issued by the University of Sfax, Tunisia, and approved by the Committee of Animal Ethics. The animals were kept in separate cages to avoid licking or biting of inflammatory areas by other animals.

2.3. Experimental Protocol. Before inducing the paw edema, a total of 36 rats were divided randomly into six equal groups:

Group 1: the rats were normal, and they did not undergo any inflammatory reaction, used as a control group.

Group 2: the rats were injected with carrageenan and treated with a normal saline (normal saline-treated group).

Group 3: the rats were injected with carrageenan topically treated with a reference drug "Inflocine ${ }^{\circledR ”}(2 \mathrm{mg} / \mathrm{paw})$ (reference group).

Groups 4, 5, and 6: the rats were injected with carrageenan and topically treated with pumpkin, linseed, and prickly pear extracted oils ( $25 \mu \mathrm{l} / \mathrm{paw}$ ), respectively (oiltreated groups). The dose of " $25 \mu \mathrm{l} /$ paw" was experimentally optimized to cover the total paw edema and to grant an antiinflammatory efficiency.

2.4. Model of Carrageenan-Induced Paw Edema. The antiinflammatory activity was assessed by the in vivo experimental model for screening the acute inflammation using carrageenan-induced rat paw [17].

Acute inflammation was induced by the subplantar administration of $100 \mu \mathrm{l}$ of $1 \%$ freshly prepared solution of carrageenan in a normal saline in the right hind paw of each rat.

The paw thickness was measured with a digital caliper at $1,2,3,4$, and 5 hours after carrageenan injection. To standardize measurements, they were performed in a transverse technique in the midplantar surface of the rat paw for all time points.

The increase in paw edema at the time $(t)$ was calculated using the following formula:

Paw thickness $(t)$ - Paw thickness $(t 0)$, where the paw volume $(t 0)$ was measured on time 0 before the carrageenan injection.

2.5. Blood Sample Collection. Five hours after carrageen induction, the rats were anesthetized by $50 \mathrm{mg} / \mathrm{kg}$ ketamine intramuscularly injected, and blood samples were collected with heparin through cardiac puncture. Plasma samples were drawn from blood after centrifugation at $3000 \mathrm{rpm}$ for 15 minutes and were stored at $-80^{\circ} \mathrm{C}$ until biochemical analysis. To eliminate interassay variance, all samples were analyzed in the same assay run. All assays were performed in triplicate in the same laboratory with simultaneous use of a control. 


\subsection{Inflammatory Parameters}

2.6.1. Testing the Blood Count. The Sysmex KX-21N analyzer was used to determine the following hematological parameters: white blood cells and platelets.

\subsubsection{Inflammatory Biomarkers}

(1) Determination of Protein Markers of Inflammation. C-reactive protein (CRP) is a specific and reliable biomarker that followed the inflammatory process. It increases in proportion to its intensity [18]. The reactive protein was measured by a turbidimetric method using an automatic analyzer Architect Ci 4100 «ABOTT.» The CRP is expressed with $\mathrm{mg} / \mathrm{l}$.

(2) Fibrinogen Assay of Plasma. The plasma fibrinogen concentration was determined by the Clauss clotting method [19] measured on the STA ${ }^{\circledR}$ analyzer. The principle test measures the conversion rate of fibrinogen into fibrin in the diluted sample in the presence of an excess of thrombin and records the clotting time. The clotting time is inversely proportional to the level of fibrinogen in the plasma. The fibrinogen level is expressed with $\mathrm{g} / \mathrm{l}$ plasma.

\subsection{Oxidative Stress Parameters}

2.7.1. Preparation of Cytosolic Extracts. The oxidative stress parameters were determined in skin homogenates diluted in phosphate buffer ( $\mathrm{pH} 7.4$ ) and centrifuged at $9000 \mathrm{rpm}$ for 15 minutes. The resulting supernatants were used for biochemical assays.

2.7.2. Protein Quantification. Skin protein contents were measured according to Bradford method [20] using bovine serum albumin as standard.

2.7.3. Thiobarbituric Acid Reactive Substances (TBARS) Assay. The assay of thiobarbituric acid reactive substances (TBARS) measures malondialdehyde (MDA) present in the sample, as well as malondialdehyde generated from lipid hydroperoxides by the hydrolytic conditions of the reaction. Tissue malondialdehyde concentrations were monitored spectrophotometrically according to the method of Esterbauer [21]. In brief, an aliquot of tissue extract supernatant was mixed with $50 \mu \mathrm{l}$ of TBS buffer and $125 \mu \mathrm{l}$ of $20 \%$ trichloroacetic acid and centrifuged at $1000 \mathrm{rpm}$ for 10 minutes. A volume of $160 \mu \mathrm{l}$ of thiobarbituric acid reagent was added to $200 \mu \mathrm{l}$ of supernatant and $40 \mu \mathrm{l}$ Tris- $\mathrm{HCl}(0.6 \mathrm{~mol} / \mathrm{l})$ and heated at $80^{\circ} \mathrm{C}$ for 10 minutes. The mixture was then cooled and measured for absorbance at $532 \mathrm{~nm}$ using a spectrophotometer. The malondialdehyde values were calculated using 1,1,3,3-tetraethoxypropane as standard and expressed as nmol of malondialdehyde per gram of protein.

2.7.4. Advanced Oxidation of Protein Products (AOPP) Assay. Advanced oxidation protein product (AOPP) levels were determined according to the method described by Kayali et al. [22]. Briefly, $0.4 \mathrm{ml}$ of the supernatant of tissue homogenate was treated with $0.8 \mathrm{ml}$ phosphate buffer $(0.1 \mathrm{~mol} / \mathrm{l}$; $\mathrm{pH} 7.4$ ). After 2 minutes, $0.1 \mathrm{ml}$ of $1.16 \mathrm{~mol} / 1$ potassium iodide was added to the tube followed by $0.2 \mathrm{ml}$ of acetic acid. The absorbance of the reaction mixture was immediately recorded at $340 \mathrm{~nm}$. The concentration of AOPP is expressed as $\mu$ moles per milligram of protein.

2.8. Antioxidant Enzyme Activities. The activity of antioxidants, namely, superoxide dismutase, catalase, and glutathione peroxidase, was measured in untreated and treated skin tissue homogenate.

2.8.1. Superoxide Dismutase (SOD) Activity Assay. The superoxide dismutase (SOD) activity was estimated according to the method described by Asada et al. [23]. Superoxide radicals are generated in riboflavin, methionine, and illuminate and assayed by the reduction of NBT to form blue formazan $(\mathrm{NBT} 2+)$. All the solutions were prepared in phosphate buffer ( $\mathrm{pH} 7.4)$. The photo-induced reactions were performed using fluorescent lamps $(20 \mathrm{~W})$. The absorbance was measured at $580 \mathrm{~nm}$. One unit of SOD activity is defined as the amount of enzyme required to cause $50 \%$ inhibition of the reduction of NBT measured at $580 \mathrm{~nm}$.

2.8.2. Catalase Activity Assay. The catalase activity was assessed following the method of Aebi [24]. Briefly, $20 \mu \mathrm{l}$ of homogenate tissue was added to $980 \mu \mathrm{l}$ of $\mathrm{H} 2 \mathrm{O} 2$ solution (containing $0.5 \mathrm{~mol} / 1 \mathrm{H} 2 \mathrm{O} 2$ and $0.1 \mathrm{~mol} / 1$ phosphate buffer). Catalase activity was determined by monitoring the $\mathrm{H} 2 \mathrm{O} 2$ decomposition which was measured spectrophotometrically by the decrease in absorbance at $240 \mathrm{~nm}$. Enzyme activity was calculated using a molar extinction coefficient and expressed as $\mu \mathrm{mol} \mathrm{H} 2 \mathrm{O} 2$ consumed $/ \mathrm{min} / \mathrm{mg}$ of protein ( $\mu \mathrm{M} /$ minute/mg protein).

2.8.3. Glutathione Peroxidase (GPx) Activity Assay. The glutathione peroxidase (GPx) activity was determined according to Flohe and Gunzler method [25]. For the enzyme reaction, $200 \mu \mathrm{l}$ of tissue homogenates was placed into a tube and mixed with $400 \mu \mathrm{l}$ glutathione (GSH) and $200 \mu \mathrm{l}$ of potassium sodium phosphate buffer. After 5 minutes of incubation at $25^{\circ} \mathrm{C}, 200 \mu \mathrm{l}$ of $\mathrm{H} 2 \mathrm{O} 2$ was added, and after 10 minutes, the reaction was terminated by the addition of $1 \mathrm{ml}$ TCA (5\%). Then, the mixture was centrifuged at $3000 \mathrm{rpm}$ for 10 minutes, and the supernatant was collected. $480 \mu \mathrm{l}$ of the supernatant was placed into a cuvette, and $2.2 \mathrm{ml}$ of disodium hydrogen phosphate (Na2HPO4) and $320 \mu \mathrm{l}$ of $0.4 \mathrm{mg} / \mathrm{ml}$ $5,5^{\prime}$-dithio-bis (2-nitrobenzoic acid) (DTNB) were added for color development. The absorbance at wavelength $412 \mathrm{~nm}$ was measured. The enzyme activity was calculated as a decrease in GSH within the reaction time as compared to that in the nonenzyme reaction and expressed as $\mu$ moles of $\mathrm{GSH} / \mathrm{min} / \mathrm{mg}$ of protein.

2.9. Histological Evaluation. Five hours after carrageenan injection, the rats were sacrificed and autopsy samples were taken from the middle of the treated paw tissues for histopathological assessment. The sample tissues were fixed in neutral buffered formalin solution (10\%), embedded in paraffin wax, cut into 5 - $\mu \mathrm{m}$-thick sections, and stained with hematoxylin-eosin. The slides were photographed with an 
Olympus U-TU1X-2 camera connected to an Olympus CX41 microscope (Tokyo, Japan).

2.10. Statistical Analysis. The data obtained were analyzed via SPSS software. Quantitative variables were presented as the mean \pm standard deviation (SD) for each group. Statistical comparisons between the groups were carried out using ANOVA followed by the Tukey test. Differences between groups were considered statistically significant at $p$ value $<0.05$.

\section{Results}

3.1. Size of Paw Edema. The evolution size of the edema of each studied group was monitored during 5 hours after carrageenan injection. The results are shown in Figure 1.

The injection of the carrageenan at the front part of the right paw led to an increase in the paw thickness. The maximum size was observed 3 hours after carrageenan injection. A significant reduction in the size of the edema was observed in the oil-treated group. This reduction was better than that of the rats of the reference group. Prickly pear oil-treated group resulted in a significant increase in the paw edema size compared to all the studied groups.

3.2. White Blood Cells and Platelets Numbers. Hematological parameters were assessed by monitoring the numbers of white blood cells and blood platelets. As shown in Figures 2 and 3 , the numbers of white blood cells and platelets were significantly increased in group 2 (normal saline-treated group) compared to the control group. In comparison with group 2, the oil-treated groups and the reference group showed a significant decrease in white blood cell (WBC) and platelet counts without reaching the normal counts of the control group.

3.3. Inflammatory Biomarkers: CRP and Fibrinogen Concentrations. Compared to the control group, group 2 (normal saline-treated group) showed a highly significant increase in mean blood concentrations of CRP and fibrinogen. The oil-treated groups and the reference group showed a significant decrease in the concentration of these inflammatory biomarkers compared to those of group 2; however, these concentrations did not reach the concentration of the control group (Figures 4 and 5).

3.4. Assessment of Lipid Peroxidation. The results of the skin lipid peroxidation are monitored in Figure 6. Data showed that carrageenan injection led to a significant increase in skin TBARS concentration. Compared to group 2, the oil-treated groups and the reference group exhibited a significant decrease $(p \leq 0.001)$ in skin TBARS concentrations. The TBARS concentrations of the oil-treated groups were similar to that of the reference group without reaching the normal concentration.

3.5. Assessment of Advanced Oxidized Protein Products $(A O P P)$. After acute inflammation, proteins are susceptible to oxidative modifications that lead to the production of carbonylated proteins. The skin AOPP concentrations are

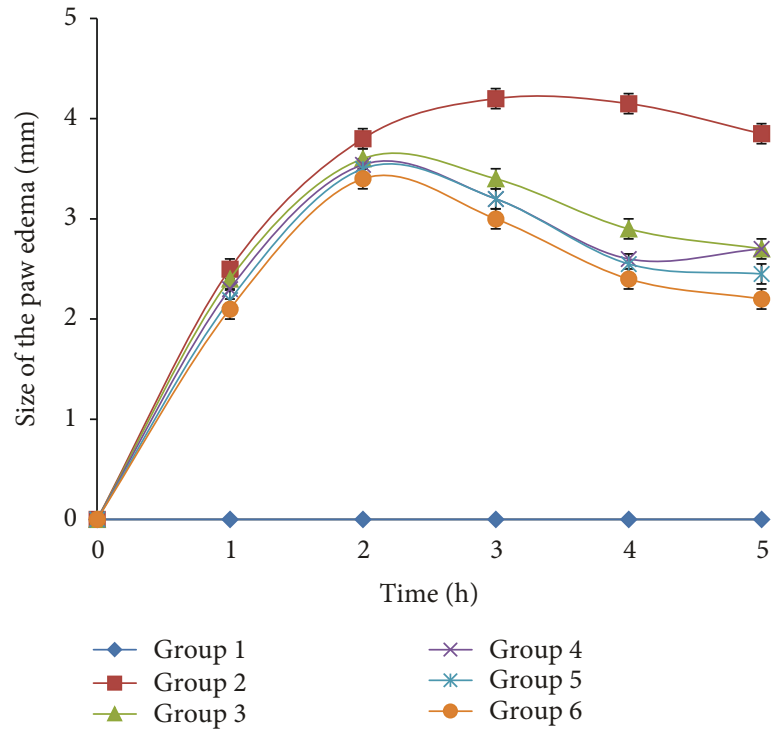

FIgURe 1: The evolution size of the paw edema during 5 hours after carrageenan injection in different experimental rat groups. All values are mean \pm S.D. ( $n=6 /$ group $)$. Group 1: normal rats (control group); group 2: normal saline-treated group; group 3: “Inflocine ${ }^{\circledR ”}$-treated rats (reference group); group 4: pumpkin oiltreated group; group 5: linseed oil-treated group; group 6: prickly pear oil-treated group.

illustrated in Figure 7. The concentration of the advanced oxidized protein products was significantly higher in group 2 (normal saline-treated group) than in the control group. The topical application of the tested oils seemed to significantly reduce the skin AOPP concentration.

\subsection{Exploring the Antioxidant Status}

3.6.1. Superoxide Dismutase (SOD) Activity. The injection of the carrageenan led to a significant decrease in skin SOD activity of $57.58 \%$ in group 2 (normal saline-treated group) compared to the control group $(p \leq 0.001)$. However, the oil-treated groups showed a significant increase in skin SOD activity compared to group 2 . There was no significant difference between the skin SOD activities of the oil-treated groups and the reference group (Figure 8).

3.6.2. Catalase (CAT) Activity. Group 2 (normal salinetreated group) revealed a significant decrease in the skin catalase activity of $32.53 \%$ compared to the control group. However, the skin catalase activities of the oil-treated groups were similar to that of control and reference groups (Figure 9).

3.6.3. Glutathione Peroxidase (GPx) Activity. The injection of the carrageenan induced a significant decrease in the skin GPx activity of $51.07 \%$ compared to the control group. However, the oil-treated groups depicted a significant increase in the skin GPx activity compared to group 2 . The skin GPx activities of the oil-treated groups were similar to that of the reference group (Figure 10). 


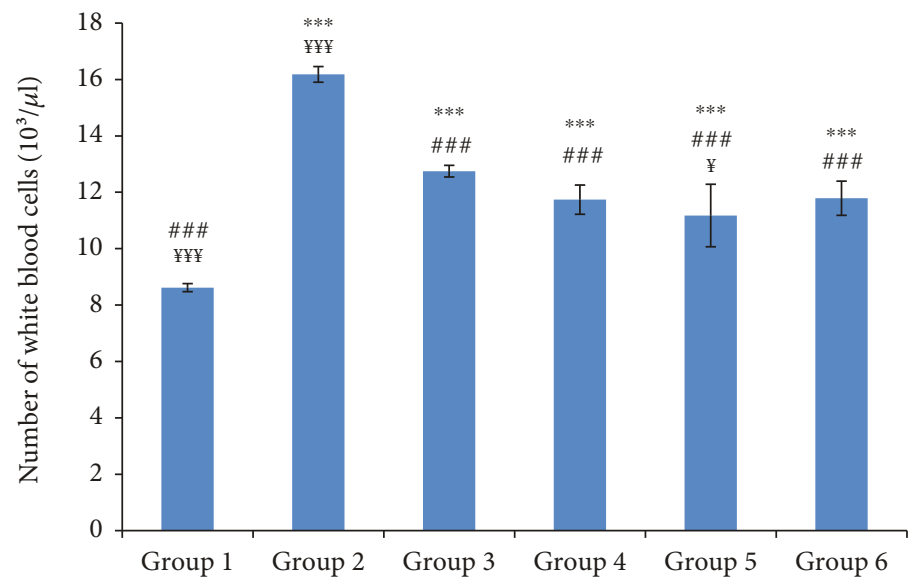

Figure 2: The number of white blood cells in different experimental rat groups five hours after carrageenan injection. All values are mean \pm S.D. ( $n=6$ /group). Group 1: normal rats (control group); group 2: normal saline-treated group; group 3: "Inflocine ${ }^{\circledR}$-treated rats (reference group); group 4: pumpkin oil-treated group; group 5: linseed oil-treated group; group 6: prickly pear oil-treated group. ${ }^{* * *} p \leq 0.001$ : highly significant difference compared to group 1 ; ${ }^{\# \# \#} p \leq 0.001$ : highly significant difference compared to group 2 ; ¥¥¥ $p \leq 0.001$ : highly significant difference compared to group $3 ;{ }^{¥} p \leq 0.05$ : significant difference compared to group 3 .

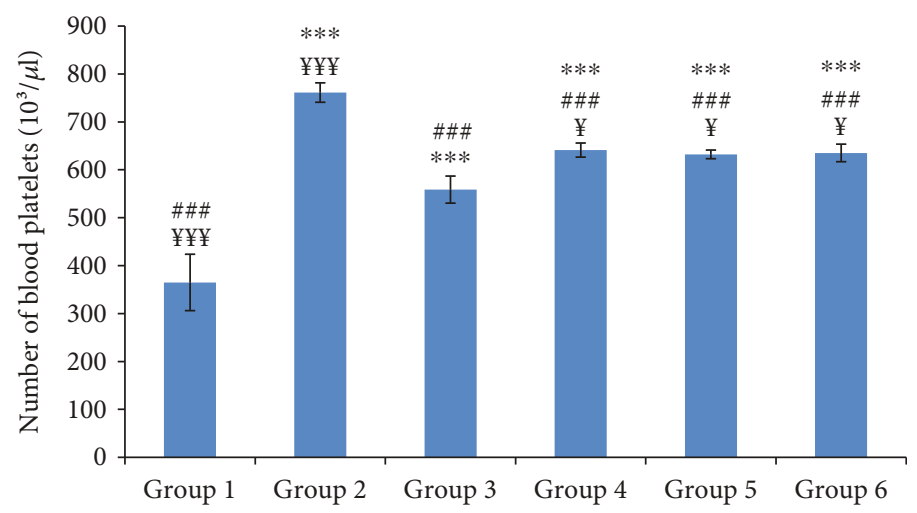

FIGURE 3: The number of blood platelets in different experimental rat groups five hours after carrageenan injection. All values are mean \pm S.D. ( $n=6$ /group). Group 1: normal rats (control group); group 2: normal saline-treated group; group 3: "Inflocine ${ }^{\circledR ”-t r e a t e d ~ r a t s ~(r e f e r e n c e ~}$ group); group 4: pumpkin oil-treated group; group 5: linseed oil-treated group; group 6: prickly pear oil-treated group. ${ }^{* * *} p \leq 0.001$ : highly significant difference compared to group 1 ; ${ }^{\# \# \#} p \leq 0.001$ : highly significant difference compared to group 2 ; ${ }^{¥ ¥ ¥} p \leq 0.001$ : highly significant difference compared to group $3 ;{ }_{p}^{¥} p \leq 0.05$ : significant difference compared to group 3 .

3.7. Histopathological Examination. The microscopic examination of the skin specimen of group 2 (normal saline-treated group) revealed the presence of interstitial edema; the predominance of inflammatory cells in the deep dermis associated with vascular congestion (hyperemia) and dilated capillaries. However, the skin specimen of the oil-treated groups and the reference group showed a significant decrease in inflammatory cells in the dermis and inside the blood vessels. These inflammatory signs seemed to be less significant in prickly pear oil-treated biopsies (Figure 11).

\section{Discussion}

The carrageenan-induced paw edema in rat is an acute inflammation model widely used for the screening of synthetic or natural anti-inflammatory products [26]. The acute inflammatory response is a protective mechanism of the body to remove the injurious stimuli that involve local cellular and vascular processes following tissue damage [1].

In this respect, this study aims at assessing the antiinflammatory effect of pumpkin, linseed, and prickly pear extracted oils using the carrageenan-induced paw model compared to a nonsteroidal anti-inflammatory drug "Inflocine ${ }^{\circledR}$." As oxidative stress plays a key role in inflammatory processes, the tested oils were assessed for their effect on inflammatory mediators and oxidative stress markers in acute inflammation.

In comparison to the control group, we noticed that the normal saline-treated group had a significant paw thickness increase which peaked at 3 hours after carrageenan injection. This finding was also described by Umamageswari and Maniyar [27]. Indeed, carrageenan induced an acute inflammatory reaction typically characterized by vasodilation and tissue swelling. This inflammatory exudate is mainly composed of polymorphonuclear leukocytes [28]. The acute 


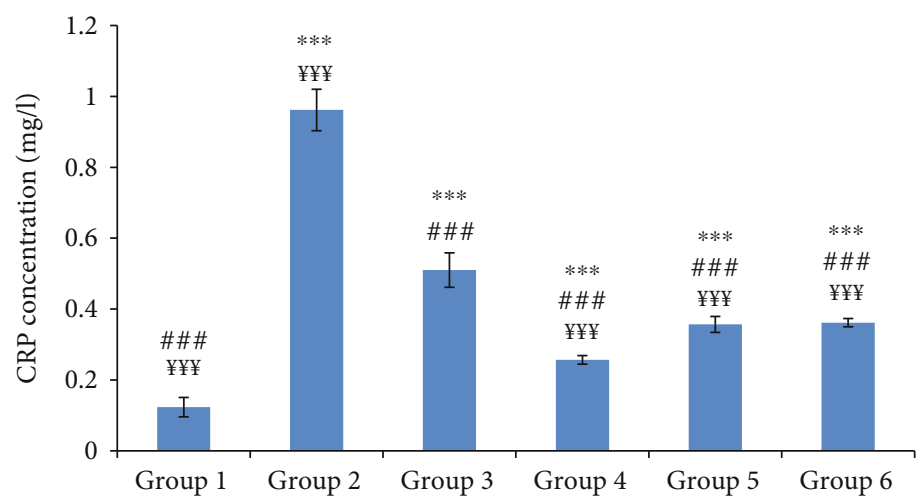

FIGURE 4: C-reactive protein (CRP) concentration in different experimental rat groups five hours after carrageenan injection. All values are mean \pm S.D. ( $n=6$ /group). Group 1: normal rats (control group); group 2: normal saline-treated group; group 3: "Inflocine ${ }^{\circledR ”}$-treated rats (reference group); group 4: pumpkin oil-treated group; group 5: linseed oil-treated group; group 6: prickly pear oil-treated group. ${ }^{* * *} p \leq 0.001$ : highly significant difference compared to group $1 ;{ }^{\# \# \#} p \leq 0.001$ : highly significant difference compared to group 2 ; ${ }^{\text {\#¥ }} p \leq 0.001$ : highly significant difference compared to group 3.

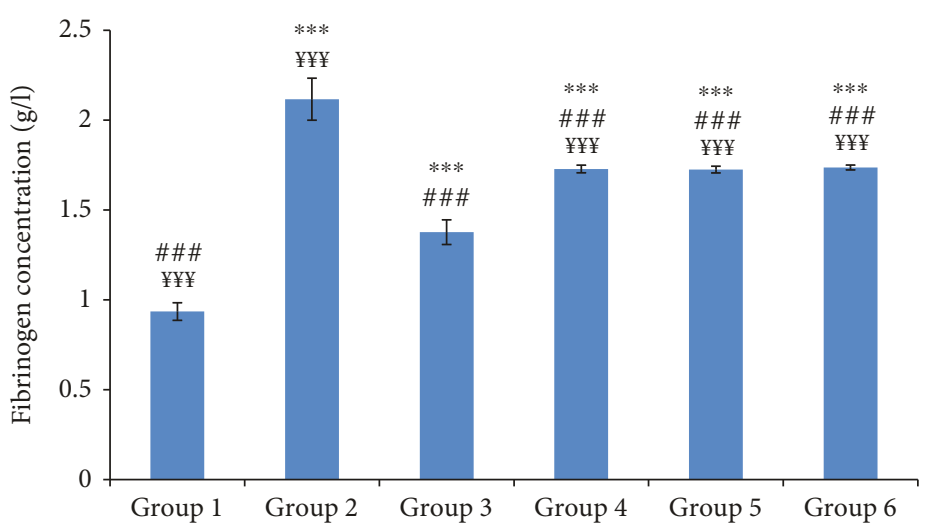

FIGURE 5: The fibrinogen concentration in different experimental rat groups five hours after carrageenan injection. All values are mean \pm S.D. ( $n=6$ /group). Group 1: normal rats (control group); group 2: normal saline-treated group; group 3: "Inflocine ${ }^{\circledR ”-t r e a t e d ~ r a t s ~(r e f e r e n c e ~}$ group); group 4: pumpkin oil-treated group; group 5: linseed oil-treated group; group 6: prickly pear oil-treated group. ${ }^{* * *} p \leq 0.001$ : highly significant difference compared to group $1 ;{ }^{\# \# \#} p \leq 0.001$ : highly significant difference compared to group 2 ; ${ }^{¥ ¥ ¥} p \leq 0.001$ : highly significant difference compared to group 3.

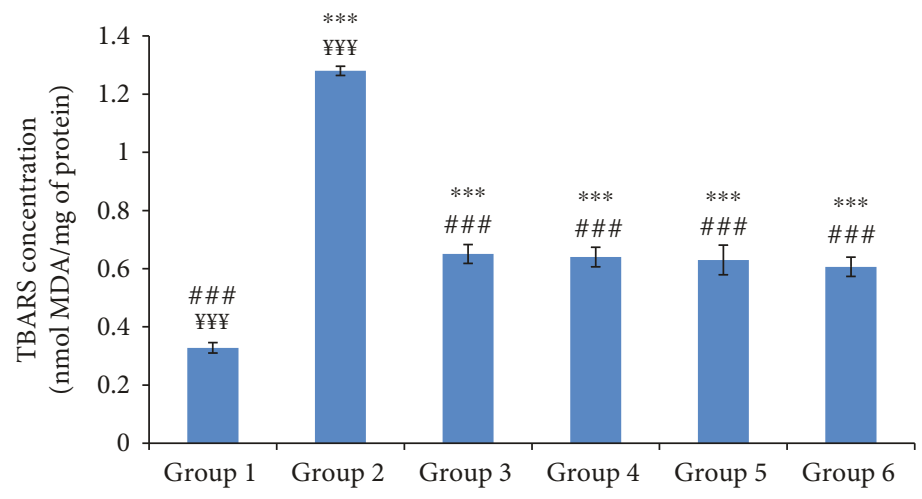

FIGURE 6: The skin thiobarbituric acid reactive substances (TBARS) concentration of different experimental rat groups five hours after carrageenan injection. All values are mean \pm S.D. ( $n=6$ /group). Group 1: normal rats (control group); group 2: normal saline-treated group; group 3: "Inflocine ${ }^{\circledR ”}$-treated rats (reference group); group 4: pumpkin oil-treated group; group 5: linseed oil-treated group; group 6: prickly pear oil-treated group. ${ }^{* * *} p \leq 0.001$ : highly significant difference compared to group $1 ;{ }^{\# \# \#} p \leq 0.001$ : highly significant difference compared to group 2 ; ${ }^{\text {¥¥ }} p \leq 0.001$ : highly significant difference compared to group 3 . 


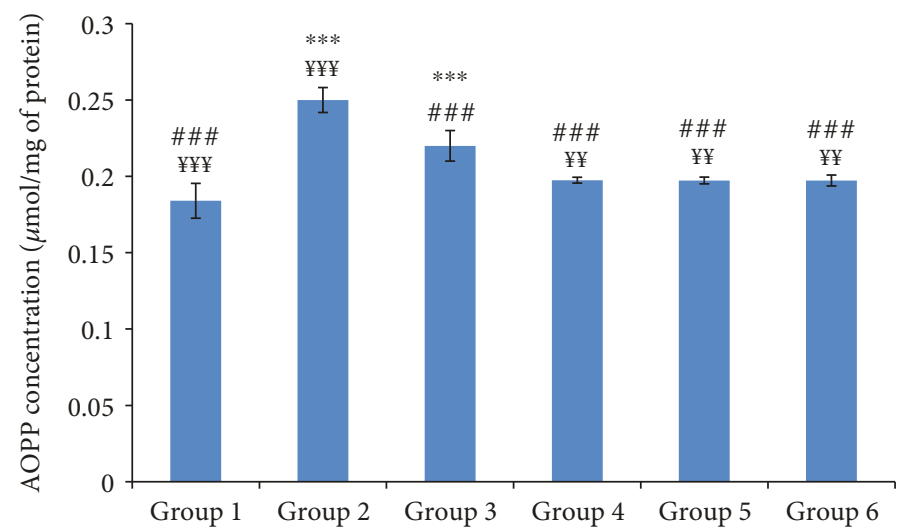

FIGURE 7: The skin advanced oxidation protein product (AOPP) concentration of different experimental rat groups. All values are mean \pm S.D. ( $n=6$ /group). Group 1: normal rats (control group); group 2: normal saline-treated group; group 3: "Inflocine ${ }^{\circledR}$-treated rats (reference group); group 4: pumpkin oil-treated group; group 5: linseed oil-treated group; group 6: prickly pear oil-treated group. ${ }^{* * *} p \leq 0.001$ : highly significant difference compared to group $1 ;{ }^{\# \# \#} p \leq 0.001$ : highly significant difference compared to group 2 ;

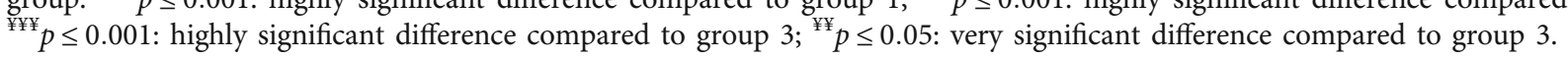

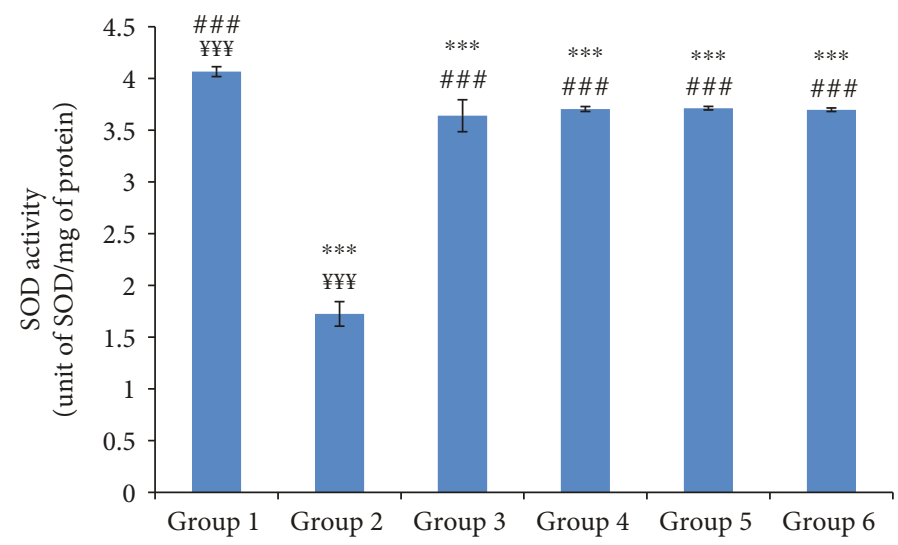

FIGURE 8: The skin superoxide dismutase (SOD) activity of different experimental rat groups. All values are mean \pm S.D. ( $n=6 /$ group). Group 1: normal rats (control group); group 2: normal saline-treated group; group 3: “Inflocine ${ }^{\circledR ”}$-treated rats (reference group); group 4: pumpkin oil-treated group; group 5: linseed oil-treated group; group 6: prickly pear oil-treated group. ${ }^{* * *} p \leq 0.001$ : highly significant difference compared to group 1; ${ }^{\# \#} p \leq 0.001$ : highly significant difference compared to group 2 ; ${ }^{¥ ¥} p \leq 0.001$ : highly significant difference compared to group 3.

inflammatory response is actually triggered by the release of mediators such as histamine and serotonin in the first few hours. The latter are related to the release of prostaglandins, proteases, and superoxide radicals. These mediators are responsible for the vasodilation of the vessels, the vascular hyperpermeability, the redness, and the edema [29, 30].

Three hours after carrageenan injection, the reference group and the oil-treated groups showed a significant reduction in the paw thickness compared to the carrageenan treated group. Indeed, it was reported that the injection of carrageenan induced a peak in COX-2 concentration one hour after the injection. This peak was associated with an increase in the synthesis of prostaglandins involved in the inflammatory process [31]. This may explain the late effect of nonsteroidal anti-inflammatory drugs such as "Inflocine ${ }^{\circledR}$ " whose effect appeared only after 2 hours. This effect was related to its mode of action which involves the inhibition of prostaglandin synthesis induced by COX-1 and COX-2 [32].

The inflammatory reaction is coordinated by various mediators that involve cell recruitment to the site of inflammation. This leads to investigating the inflammatory parameters (including CRP and fibrinogen), white blood cells, and blood platelets.

The plasma concentrations of fibrinogen and CRP were significantly increased in the normal saline-treated group compared to the control group. The CRP and fibrinogen are the protein biomarkers of inflammation that are increased during the acute inflammation [33]. Indeed, the CRP which has proinflammatory and prothrombotic effects increases the expression of tissue factor and interleukin-6. The acute inflammation was also associated with an increase of white blood cell (WBC) and platelet counts. This leukocytosis was attributed to the increase of leukocyte recruitment 


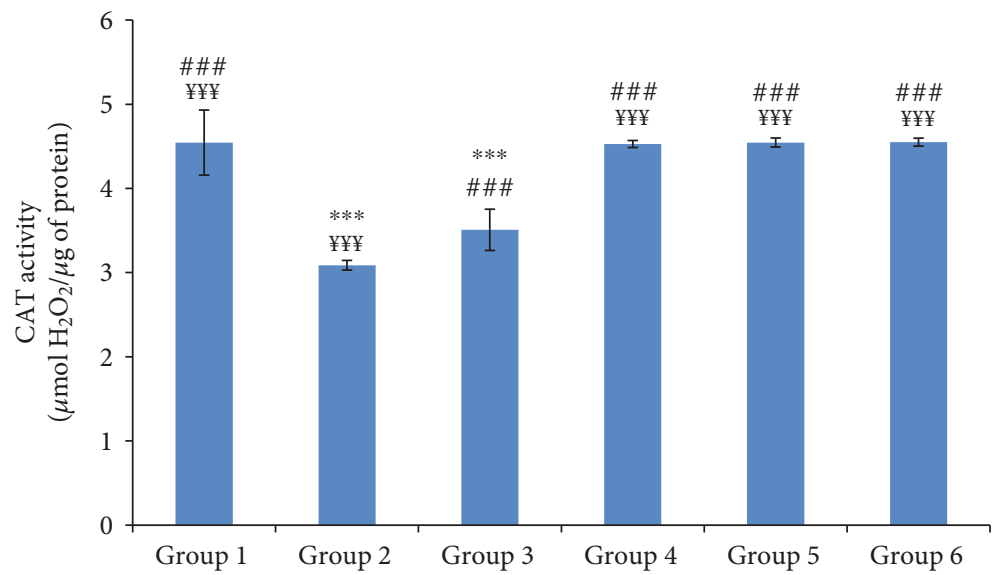

Figure 9: The skin catalase (CAT) activity of different experimental rat groups. All values are mean \pm S.D. ( $n=6 /$ group). Group 1: normal rats (control group); group 2: normal saline-treated group; group 3: "Inflocine ${ }^{\circledR ”}$-treated rats (reference group); group 4: pumpkin oiltreated group; group 5: linseed oil-treated group; group 6: prickly pear oil-treated group. ${ }^{* * *} p \leq 0.001$ : highly significant difference compared to group $1 ;{ }^{\# \# \#} p \leq 0.001$ : highly significant difference compared to group 2 ; ${ }^{\text {羊 }} p \leq 0.001$ : highly significant difference compared to group 3.

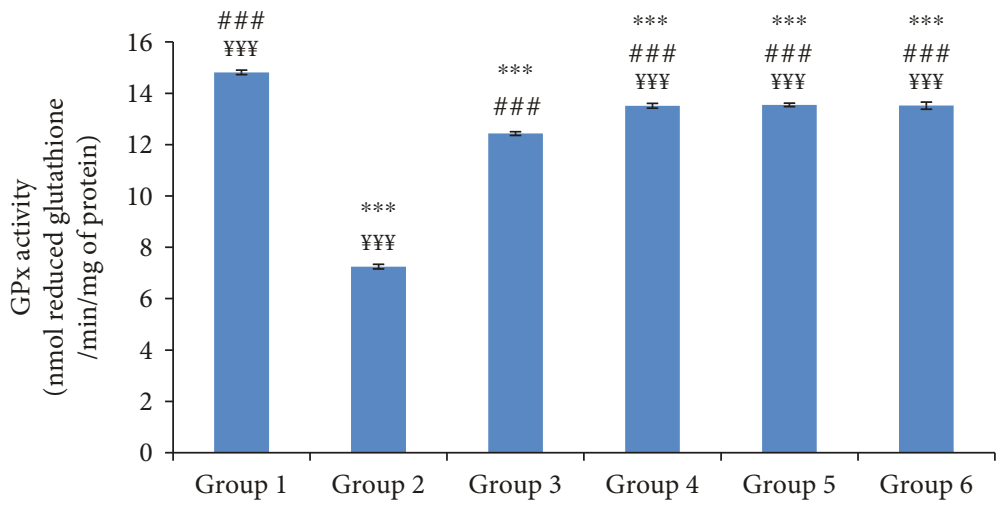

FIGURE 10: The skin glutathione peroxidase (GPx) activity of different experimental rat groups. All values are mean \pm S.D. $(n=6 /$ group). Group 1: normal rats (control group); group 2: normal saline-treated group; group 3: "Inflocine ${ }^{\circledR ”}$-treated rats (reference group); group 4: pumpkin oil-treated group; group 5: linseed oil-treated group; group 6: prickly pear oil-treated group. ${ }^{* * *} p \leq 0.001$ : highly significant difference compared to group $1 ;{ }^{\# \# \#} p \leq 0.001$ : highly significant difference compared to group 2 ; ${ }^{¥ ¥} p \leq 0.001$ : highly significant difference compared to group 3.

and could be directly proportional to the severity of the causative stress condition [34]. It was reported that carrageenan stimulated immune functions by the infiltration of WBC into the site of inflammation due to the release of proinflammatory cytokines (IL-I). The latter increased the production of both granulocyte and macrophages colonystimulating factors [35].

The significant decrease of the hematological parameters and the clinical signs in the oil-treated groups as well as in the reference group compared to the control group suggest a potent anti-inflammatory effect of the tested oils. It was reported that the anti-inflammatory drugs depleted the migration of inflammatory cells by inhibiting the release of various chemical mediators [36].

The carrageenan injection not only induced significant increase in TBARS concentration and the AOPP concentrations but also resulted in a significant decrease of the activi- ties of antioxidant enzymes (SOD, CAT, GPx). Indeed, the phospholipid bilayer of the cell membrane, which is particularly rich of polyunsaturated fatty acids and proteins, formed a target for free radical attack resulting in an increase in skin TBARS and AOPP concentrations [37]. The decrease in the activities of the antioxidant enzymes such as SOD, CAT, and GPx might be due to their excessive secondary consumption of free radicals which were generated by inflammation. Previous researches revealed that carrageenan injection caused excessive production of free radical. The involvement of oxidative stress in the acute inflammatory process had been already described by several authors [1, 38-40]. The tested oils', once in contact with the skin, lipophilic compounds (tocopherols, sterols, and polyunsaturated fatty acids) seeped into the stratum corneum by percutaneous intercellular absorption and then joined the epidermis and the dermis [41, 42]. The latter was rich in dilated blood 


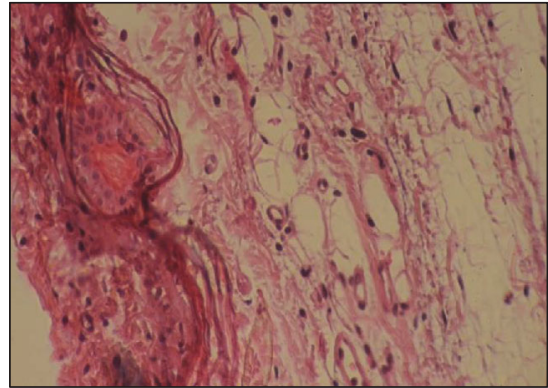

(a)

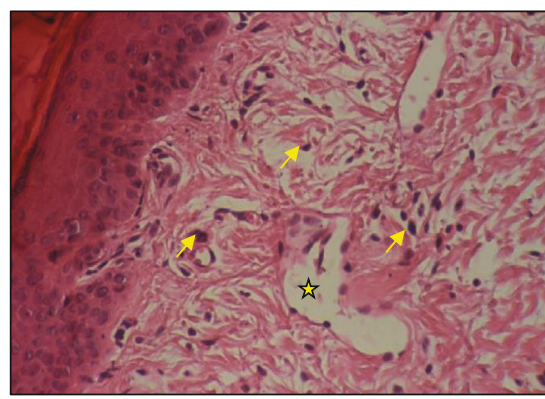

(c)

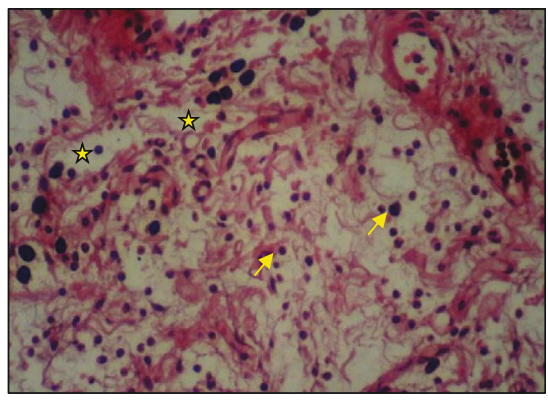

(e)

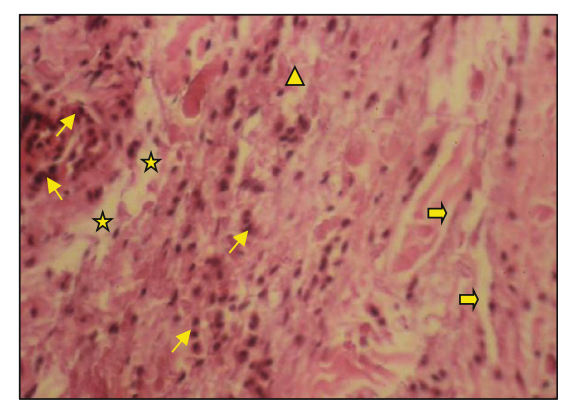

(b)

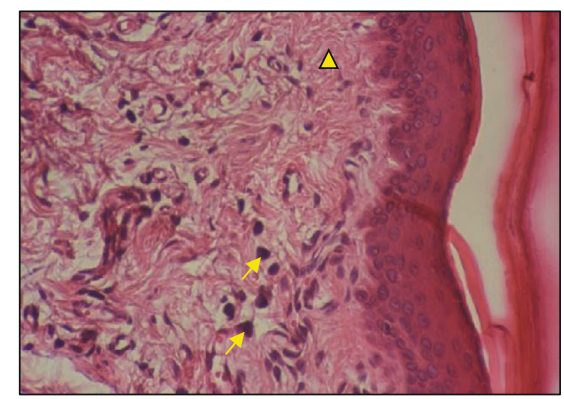

(d)

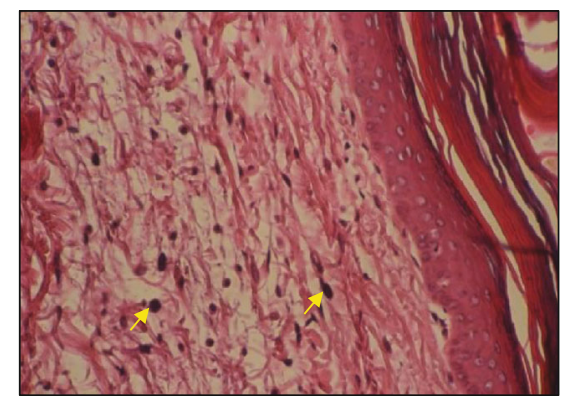

(f)

FIgURE 11: The histological features of the skin sections $(\times 400)$ of each group stained with hematoxylin-eosin five hours after carrageenan induction. (yellow star): edema; (yellow arrow): dilated vessel; (yellow slant arrow): inflammatory nucleus; (yellow triangle): vacuum cells. (a) Histological section of a normal skin area of representative control rat (control group); (b) histological section of representative normal saline-treated rat (group 2); (c) histological section of representative "Inflocine ${ }^{\circledR ”-t r e a t e d ~ r a t ~(g r o u p 3) ; ~(d) ~ h i s t o l o g i c a l ~ s e c t i o n ~ o f ~}$ representative pumpkin oil-treated rat (group 4); (e) histological section of representative linseed oil-treated rat (group 5); (f) histological section of representative prickly pear oil-treated rat (group 6).

vessels which allowed the absorption of bioactive compounds from the oil [43]. The anti-inflammatory effect of the tested oils based on the clinical and biological assessments could be related to their unsaturated fatty acids which were considered as highly active anti-inflammatory compounds acting as inhibitors of cyclo-oxygenases $[44,45]$. This effect could be also attributed to the antioxidant properties of the tested oils for their bioactive compounds such as phytosterols, tocopherols, polyphenols, and carotenoids. In fact, the lipophilic aspect of these compounds allowed them to diffuse inside the cell membrane which is rich in polyunsaturated fatty acids and protein. Then, these bioactive compounds might trap the activated oxygen species; as a consequence, the spread of both lipid and protein oxidations might be inhibited. Added to that, it was described that phytosterols, in particular $\beta$-sitosterols, and polyphenols had also antiinflammatory activities [46].
The prickly pear oil provided a better anti-inflammatory effect compared to all the tested oil. This result was closely correlated with its chemical profile, which exhibited a richness in the tocopherols and sterols [45].

\section{Conclusions}

Overall, the data of the current study highlight the antiinflammatory effect of pumpkin, linseed, and especially prickly pear extracted oils on acute inflammation through the decrease of clinical signs of inflammation, infiltration of inflammatory cells, vascular congestion, and biochemical markers. These anti-inflammatory effects elicited by the tested oils are closely associated with the amelioration of the endogenous skin antioxidant status. Thus, the tested oils may be potentially used as an anti-inflammatory component of new drugs for the treatment of acute inflammation 
without side effects. However, further studies are necessary to determine the cytokine profile and the lipid mediators of the oil-treated groups.

\section{Data Availability}

No data were used to support this study.

\section{Conflicts of Interest}

The authors report no conflicts of interest.

\section{Acknowledgments}

This research was supported by the Tunisian Ministry of Higher Education and Scientific Research.

\section{References}

[1] L. Chen, H. Deng, H. Cui et al., "Inflammatory responses and inflammation-associated diseases in organs," Oncotarget, vol. 9, no. 6, pp. 7204-7218, 2018.

[2] J. M. Bennett, G. Reeves, G. E. Billman, and J. P. Sturmberg, "Inflammation-nature's way to efficiently respond to all types of challenges: implications for understanding and managing "the epidemic" of chronic diseases," Frontiers in Medicine, vol. 5, p. 316, 2018.

[3] W. H. El-Tantawy, "Natural products for the management of hyperuricaemia and gout: a review," Archives of Physiology and Biochemistry, pp. 1-12, 2019.

[4] Z. Sahnoun, K. Jamoussi, and K. M. Zeghal, "Free radicals and antioxidants: human physiology, pathology and therapeutic aspects," Thérapie, vol. 52, no. 4, pp. 251-270, 1997.

[5] S. Bardaa, N. B. Halima, F. Aloui et al., "Oil from pumpkin (Cucurbita pepo L.) seeds: evaluation of its functional properties on wound healing in rats," Lipids in health and disease, vol. 15, no. 1, p. 73, 2016.

[6] S. Tavarini, A. Castagna, G. Conte et al., "Evaluation of chemical composition of two linseed varieties as sources of healthbeneficial substances," Molecules, vol. 24, no. 20, p. 3729, 2019.

[7] I. Khémiri, B. EssghaierHédi, N. SadfiZouaoui, N. Ben Gdara, and L. Bitri, "The antimicrobial and wound healing potential of Opuntiaficusindica L. inermis extracted oil from Tunisia," Evidence-based Complementary and Alternative Medicine, vol. 2019, 10 pages, 2019.

[8] G. G. Adams, S. Imran, S. Wang et al., "The hypoglycaemic effect of pumpkins as anti-diabetic and functional medicines," Food Research International, vol. 44, no. 4, pp. 862-867, 2011.

[9] N. K. K. Boaduo, D. Katerere, J. N. Eloff, and V. Naidoo, "Evaluation of six plant species used traditionally in the treatment and control of diabetes mellitus in South Africa using in vitro methods," Pharmaceutical Biology, vol. 52, no. 6, pp. 756-761, 2014.

[10] M. Nishimura, T. Ohkawara, H. Sato, H. Takeda, and J. Nishihira, "Pumpkin seed oil extracted from Cucurbita maxima improves urinary disorder in human overactive bladder," Journal of Traditional and Complementary Medicine, vol. 4, no. 1, pp. 72-74, 2014.

[11] S. Bardaa, D. Moalla, S. Ben Khedir, T. Rebai, and Z. Sahnoun, "The evaluation of the healing proprieties of pumpkin and lin- seed oils on deep second-degree burns in rats," Pharmaceutical Biology, vol. 54, no. 4, pp. 581-587, 2015.

[12] A. Goyal, V. Sharma, N. Upadhyay, S. Gill, and M. Sihag, "Flax and flaxseed oil: an ancient medicine \& modern functional food," Journal of Food Science \& Technology, vol. 51, no. 9, pp. 1633-1653, 2014.

[13] L. Zarepoor, J. T. Lu, C. Zhang et al., "Dietary flaxseed intake exacerbates acute colonic mucosal injury and inflammation induced by dextran sodium sulfate," American Journal of Physiology-Gastrointestinal and Liver Physiology, vol. 306, no. 12, pp. G1042-G1055, 2014.

[14] M. Ennouri, B. Evelyne, M. Laurence, and A. Hamadi, "Fatty acid composition and rheological behaviour of prickly pear seed oils," Food Chemistry, vol. 93, no. 3, pp. 431-437, 2005.

[15] A. Berraaouan, A. Ziyyat, H. Mekhfi et al., "Evaluation of antidiabetic properties of cactus pear seed oil in rats," Pharmaceutical Biology, vol. 52, no. 10, pp. 1286-1290, 2014.

[16] S. Bardaa, N. Chabchoub, M. Jridi et al., "The effect of natural extracts on laser burn wound healing," Journal of Surgical Research, vol. 201, no. 2, pp. 464-472, 2015.

[17] M. Goyal, M. Ghosh, B. P. Nagori, and D. Sasmal, "Analgesic and anti-inflammatory studies of cyclopeptide alkaloid fraction of leaves of Ziziyphus nummularia," Saudi Journal of Biological Sciences, vol. 20, no. 4, pp. 365-371, 2013.

[18] K. L. Strutz, "Developmental origins of chronic inflammation: a review of the relationship between birth weight and Creactive protein," Annals of Epidemiology, vol. 25, no. 7, pp. 539-543, 2015.

[19] A. Clauss, "Gerinnungsphysiologische Schnellmethode zur Bestimmung des fibrinogens," Acta Haematologica, vol. 17, no. 4, pp. 237-246, 1957.

[20] M. M. Bradford, "A rapid and sensitive method for the quantitation of microgram quantities of protein utilizing the principle of protein-dye binding," Analytical Biochemistry, vol. 72, no. 1-2, pp. 248-254, 1976.

[21] H. Esterbauer, "Cytotoxicity and genotoxicity of lipidoxidation products," The American Journal of Clinical Nutrition, vol. 57, no. 5, pp. 779S-786S, 1993.

[22] R. Kayali, U. Çakatay, T. Akçay, and T. Altuğ, "Effect of alphalipoic acid supplementation on markers of protein oxidation in post-mitotic tissues of ageing rat," Cell Biochemistry \& Function, vol. 24, no. 1, pp. 79-85, 2006.

[23] K. Asada, M. A. Takahashi, and M. Nagate, "Assay and inhibitors of spinach superoxide dismutase," Agricultural \& Biological Chemistry, vol. 38, no. 2, pp. 471-473, 2014.

[24] H. Aebi, "[13] Catalase in vitro," Methods in Enzymology, vol. 105, no. 1, pp. 121-126, 1984.

[25] L. Flohe and W. A. Gunzler, "[12] Assays of glutathione peroxidase," Methods in Enzymology, vol. 105, pp. 114-120, 1984.

[26] A. A. Hemmati, H. Kalantari, A. Siahpoosh, B. Ghorbanzadeh, and H. Jamali, "Anti-inflammatory effect of hydroalcoholic extract of the washingtoniafilifera seeds in carrageenaninduced paw edema in rats," Jundishapur Journal of Natural Pharmaceutical Products, vol. 10, no. 1, article e19887, 2015.

[27] M. S. Umamageswari and Y. A. Maniyar, "Evaluation of antiinflammatory activity of aqueous extract of leaves of Solanum melongena linn. In experimental animals," Journal of Clinical \& Diagnostic Research, vol. 9, no. 1, pp. FF01-FF03, 2015.

[28] N. A. El-Shitany, L. A. Shaala, A. T. Abbas et al., "Evaluation of the anti-inflammatory, antioxidant and immunomodulatory effects of the organic extract of the red sea marine sponge 
Xestospongia testudinaria against carrageenan induced rat paw inflammation," PLoS One, vol. 10, no. 9, article e0138917, 2015.

[29] C. J. Morris, "Carrageenan-induced paw edema in the rat and mouse," Inflammation Protocols, pp. 115-121, 2003.

[30] Y. H. Du, R. Z. Feng, Q. Li et al., “Anti-inflammatory activity of leaf essential oil from Cinnamomum longepaniculatum (Gamble) N. Chao," International Journal of clinical \& Experimental Medicine, vol. 7, no. 12, pp. 5612-5620, 2014.

[31] I. Posadas, M. Bucci, F. Roviezzo et al., "Carrageenan-induced mouse paw oedema is biphasic, age-weight dependent and displays differential nitric oxide cyclooxygenase-2 expression," British Journal of Pharmacology, vol. 142, no. 2, pp. 331-338, 2004.

[32] B. Naveau, "Dual inhibition of cyclo-oxygenases and 5-lipoxygenase: a novel therapeutic approach to inflammation?," Joint Bone Spine, vol. 72, no. 3, pp. 199-201, 2005.

[33] E. Gruys, M. J. M. Toussaint, T. A. Niewold, and S. J. Koopmans, "acute phase reaction and acute phase proteins," Journal of Zhejiang University Science. B, vol. 6, no. 11, pp. 1045-1056, 2005.

[34] G. E. Çelik, J. T. Schroeder, R. G. Hamilton, S. S. Saini, and N. F. Adkinson, "Effect of in vitro aspirin stimulation on basophils in patients with aspirin-exacerbated respiratory disease," Clinical \& Experimental Allergy, vol. 39, no. 10, pp. 1522-1531, 2009.

[35] N. S. Umapathy, Z. Fan, E. A. Zemskov, I. B. Alieva, S. M. Black, and A. D. Verin, "Molecular mechanisms involved in adenosine-induced endothelial cell barrier enhancement," Vascular Pharmacology, vol. 52, no. 5-6, pp. 199-206, 2010.

[36] C. A. Dinarello, "Anti-inflammatory agents: present and future,” Cell, vol. 140, no. 6, pp. 935-950, 2010.

[37] C. de la Haba, J. R. Palacio, P. Martínez, and A. Morros, "Effect of oxidative stress on plasma membrane fluidity of THP-1 induced macrophages," BiochimicaetBiophysicaActa (BBA)Biomembranes, vol. 1828, no. 2, pp. 357-364, 2013.

[38] L. Petrov, E. Tzvetanova, A. Pavlova et al., "In-vivo effects of nociceptin and its structural analogue [Orn9] nociceptin on the antioxidant status of rat blood and liver after carrageenan-induced paw inflammation," Open Medicine, vol. 5, no. 1, pp. 123-131, 2010.

[39] Z. Xu, J. Zhou, J. Cai, Z. Zhu, X. Sun, and C. Jiang, “Antiinflammation effects of hydrogen saline in LPS activated macrophages and carrageenan induced paw oedema," Journal of Inflammation, vol. 9, no. 1, p. 2, 2012.

[40] S. Vircheva, G. Nenkova, A. Georgieva et al., "Effects of desipramine on the antioxidant status in rat tissues at carrageenaninduced paw inflammation," Cell Biochemistry \& Function, vol. 30, no. 1, pp. 18-23, 2012.

[41] J. Bouwstra, G. Pilgram, G. Gooris, H. Koerten, and M. Ponec, "New aspects of the skin barrier organization," Skin Pharmacology \& Physiology, vol. 14, no. 1, pp. 52-62, 2001.

[42] M. Ponec, A. Weerheim, P. Lankhorst, and P. Wertz, "New acylceramide in native and reconstructed epidermis," Journal of Investigative Dermatology, vol. 120, no. 4, pp. 581-588, 2003.

[43] K. Kretsos, M. A. Miller, G. Zamora-Estrada, and G. B. Kasting, "Partitioning, diffusivity and clearance of skin permeants in mammalian dermis," International Journal of Pharmaceutics, vol. 346, no. 1-2, pp. 64-79, 2008.

[44] G. Calviello, H. M. Su, K. H. Weylandt, E. Fasano, S. Serini, and A. Cittadini, "Experimental Evidence of -3 Polyunsatu- rated Fatty Acid Modulation of Inflammatory Cytokines and Bioactive Lipid Mediators: Their Potential Role in Inflammatory, Neurodegenerative, and Neoplastic Diseases," BioMed Research International, vol. 2013, 13 pages, 2013.

[45] D. M. Pereira, G. Correia-da-Silva, P. Valentão, N. Teixeira, and P. B. Andrade, "Anti-inflammatory effect of unsaturated fatty acids and ergosta-7,22-dien-3-ol from Marthasterias glacialis: prevention of chop-mediated er-stress and NF- $\kappa \mathrm{B}$ activation," PLoS One, vol. 9, no. 2, article e88341, 2014.

[46] J. Niazi, V. Gupta, P. Chakarborty, and P. Kumar, “Antiinflammatory and antipyretic activity of Aleuritismoluccana leaves," Asian Journal of Pharmaceutical \& Clinical Research, vol. 3, no. 1, pp. 35-37, 2010. 